\title{
Designing a Merit Process as Intellectual Work
}

\section{David Beard}

The author is associate professor of rhetoric and scientific and technical communication at the University of Minnesota, Duluth.
Organizational worth [should be] the sole criterion for rewards. Factors irrelevant to organizational performance should be irrelevant to organizational rewards.

—James C. Hearn, "Pay and Performance in the University: An Examination of Faculty Salaries"

Annually, faculty members at most universities compete for a merit award, an increase to their base pay beyond cost of living, or an across-the-board increase. At my institution, the annual faculty information record is called a "miracle sheet." The process of preparing a record of the year's miracles is burdensome, a distraction from actually doing the work.

At worst, the annual reporting of activities becomes a conflict. The politics of academia are so vicious, the saying goes, because the stakes are so small. Faculty members can argue for hours about the relative merits of a conference or a journal as they try to divide the pie available for raises.

Is the value of a journal in its acceptance rate? in the specialized community that the journal appeals to? in its impact factor?

Similar arguments arise in teaching. Should one earn the same merit from receiving a high teaching evaluation in a required course in general education as one might earn for the same scores in a specialized course (e.g., a senior capstone)? Largeenrollment classes are the bread and butter of a department, often seen as important and subsidizing low-enrollment classes. Should those who teach large-enrollment classes be awarded more merit than those whose classes are capped at fifteen?

And how do we evaluate service-the work that no one wants to do but that is necessary for the operation of the university?

Here I survey the reasons that faculty members don't participate more fully in the construction of the process by which merit pay is awarded, then I demonstrate that the construction of these processes is intellectual work with significant consequences for the culture of the department. I focus on the process for evaluating research.

Research is worth reflection in the merit process because past scholarship reveals what we have all sensed or intuited: research (often) determines pay for university faculty members. According to Luis R. Gomez-Mejia and David B. Balkin,

The primary determinants of faculty pay, in both institutions that grant doctorates and those that do not, are the number of top-tier journal publications a faculty member has authored and changes in institutional affiliation. Teaching performance and numbers of citations, second-tier publications, and books published affect pay allocations only for faculty members who have exceptional research records. (921)

(c) David Beard

CrossRef DOI 10.1632/ade.157.45 
Designing a

Merit Process as

Intellectual Work

David Beard
Research exerts a powerful force on salary, so the ways we account for it within our merit processes have real implications.

Of course, merit calculations often also include teaching and service. As I argue for participation in designing merit-pay processes for research, the same arguments and principles may lead readers to similar reflections on teaching and service.

\section{Why Don't People Take Merit Matrix Construction Seriously?}

In many universities, merit is decided within the department, and recommendations are forwarded to the dean. This process ensures that these decisions are made by experts who understand the discipline (as well as absolving the dean of some responsibility and work).

The process by which a department head (or a departmental committee) makes these kinds of choices is the scalpel, or the ax, that we use on ourselves. But some of our colleagues don't take the construction of a merit process as seriously as others might.

Why not?

Because the amount of money awarded in the merit process is insignificant. David E. Terpstra and Andre L. Honoree describe this feeling: "Negative perceptions of pay equity may occur if an employee feels that the amount of merit pay he or she received is trivial or too small in relativity to his or her effort and performance" (43). What does the difference between one hundred and two hundred dollars make, in merit?

This opinion seems more widely found in the humanities, where mathematical literacy is weaker. If your merit award is off by one hundred dollars a year, every year, for thirty years, by the thirtieth year, you will find yourself earning seventeen thousand dollars per year less than you would have if you'd made the corrections to the matrix. That is the power of compound interest.

This resistance to the process, I cannot sympathize with. Plus or minus a hundred dollars a year feels insignificant, but over a career, it matters.

Because the merit process is designed to turn us against each other, when the administration is where our attention needs to be. Richard I. Miller summarizes this perspective in this way: merit pay procedures can be "demoralizing and sometimes antagonistic" (221). A merit system that might represent at most a few hundred dollars of income in a year becomes a site of conflict among faculty members.

Meanwhile, my most cynical colleagues argue, administration members award themselves raises far beyond that. As a result, we are fighting for scraps while the administration fights over steaks. My most cynical colleagues argue that we should focus our attention on the growth of administrative positions and salaries.

While I can agree with these principles, we can own what power we have in this process. As Marc Siegall and Chuck Worth note, in studies of faculty merit procedures, "faculty trusted their colleagues more than administrators and reported that their colleagues were better able to measure their success" (655). We are part of this process and, using our power, we can shape the fight we are asked to wage with each other. Perhaps we can turn it into something that isn't a fight at all. 
Designing a

Merit Process as

Intellectual Work

David Beard
Because the merit process is low-level administrative work. Some faculty members simply lack the patience for what they see as a low-level administrative task. As Miller describes it, "the process is derisive and time-consuming; it benefits primarily those faculty members most skilled at form-filling" (221). These folks want to keep their eyes on the research or teaching they are comfortable with instead of on the administrative work they want to avoid.

I'm of limited sympathy here, too. We all want to work within our strengths. But we should all want to work in contexts that value this work appropriately. To shape the contexts in which we work, we need to participate.

We need to see designing a merit process as intellectual work.

\section{Refiguring Merit Matrices as Intellectual Work}

It's cynical to imagine merit calculations only as low-level administrative work. Instead, following from critical perspectives within human resources management, we can envision the reporting and awarding of merit pay as a project for "mutuality" (R. Walton qtd. in Gill 3) — that is, it's a task that creates "mutual goals, influence, respect, rewards and responsibility which lead to employee commitment, resulting in better outcomes for employees and the organization" (Gill 3). Within that frame, human resources management, understood as a form of developmental humanism, emphasizes "treating employees as valued assets, a source of competitive advantage through their commitment, adaptability and high quality skills and performance" (K. Legge qtd. in Gill 3-4). ${ }^{1}$ Our goal is to re-envision the construction of a merit process as intellectual work, which produces a healthier department—and one that is respectful of the contributions of its members.

And reconceiving the merit process does more than distribute small amounts of money. It reflects the values of the organization and shapes the activities engaged within it.

At the pragmatic level, according to Miller, a good merit system would "eliminate arbitrary assessment and personal judgment; reward desired behaviors; individualize rewards by recognizing diverse attributes and activities; award merit pay to all who achieve designed goals; encourage cooperation, and discourage the kinds of competitive activities which sap morale" (221). We'll work in a better-functioning community.

At a more theoretical level, a merit pay system is a discourse of legitimation. As Derek J. Harmon, Sandy E. Green, Jr., and G. Thomas Goodnight note, "Legitimacy, defined as a generalized assumption of desirability or appropriateness of an action or idea, ... is critical for social action. ... Given that legitimacy can constrain and enable people in thought and action, ... scholars have argued that it plays a fundamental role in the maintenance and change of organizations and institutions" (76). The merit process functions to legitimate some activities and even encourage others.

Let me offer a small example. In the Department of Writing Studies at the University of Minnesota, Duluth, the members of the tenured faculty wanted to construct a culture that valued the work of our non-tenure-track faculty members 
Designing a

Merit Process as

Intellectual Work

David Beard beyond their presence in the classroom, so our process awarded merit for participating on committees. However, the maximum number of points awardable for committee activities was capped at two committees. We did not want to encourage excessive service, because excessive service might take people away from their teaching, but we did want to legitimate some committee service.

A merit process, then, does more than distribute funds. It manifests the values of the department. In so doing, it has the potential, at least, to shape the activities of faculty members. Some faculty members may be resistant to the formative power of the process. They will do what they want to do, regardless—faculty members are difficult cats to herd. The merit process will condition them to see their work as undervalued, a self-conception that can have important, negative consequences on the departmental culture.

Below I discuss some sample merit documents, fictionalized for presentation here. They are synthesized from several university or departmental matrices, to draw the reader's attention to salient details that best make a specific point. I use the tools of management studies and those of rhetorical studies to illuminate the examples at different junctures. My goal, in the end, is to invite you to see the collaborative development of a merit process as important, intellectual work.

\section{Merit Processes for Research: Comparing Holistic and Atomistic Measurements for Productivity}

This section addresses the difference between atomistic and holistic merit processes. ${ }^{2}$ The first example is modeled from a research-intensive department, and the second and third examples are from undergraduate institutions emphasizing teaching and research equally.

In the first example (app. 1), a holistic matrix, a high level of consensus needs to be reached at the front end of the process. The preamble reflects this work, defining terms and establishing collective values. Note that the preamble does nothing to establish a hierarchy of values. In rattling, for example, through a list of values like "historical, theoretical, ethnographic, archival, or textual breadth," no attempt is made to establish a hierarchy for those scholarly traditions, any more than a hierarchy is established between "awards and honors, grants, editorships, reviews, citations, prizes, presentations, organization of scholarly conferences, reprints, multiple editions, and translations." The work of consensus is front-loaded; these are the forms of work that the department values, full stop.

In this way, the criteria or preamble section of the merit matrix functions as a kind of constitutional preamble. Consonant with legal rhetorical research (e.g., Orgad), this preamble establishes the common set of values for the department. This community of scholars values venue, scope, originality, and visibility in scholarship and creative activity.

Within those statements of value, then, faculty members identify themselves within three profiles. This follows the model of "identification" advanced by Kenneth Burke in his Rhetoric of Motives: "A is not identical with his colleague, B. But insofar as their interests are joined, $\mathrm{A}$ is identified with $\mathrm{B}$. Or he may identify 
Designing a

Merit Process as

Intellectual Work

David Beard himself with $B$ even when their interests are not joined, if he assumes they are, or is persuaded to believe so" (20-21). Burke notes that identification depends on both congregration and segregation. Category 3 is written punitively: "chronically unproductive." The bulk of members of this department will, I think, congregate with category 2 in most years; they will make best efforts to remain outside (segregated from) category 3 , and they will make efforts to rise to category 1 . This is not only because they want the raise; it is because they identify, presumably, with the collective values of the department.

Dividing merit into three categories is attractive (app. 2). In the second example, a system at a Midwestern undergraduate institution goes for similar simplicity, in that it has only three tiers. This process skips the preamble. It doesn't need the preamble because its values are expressed in just one term: "peer-reviewed."

A member of this department is doing the work, then, if they are submitting work for peer review. If they are successful in such submission, they earn extra merit. The third category is not punitive; it simply indicates the minimum of participation.

As a rhetorician who studies rhetorical processes across disciplines, I would offer a warning: "peer review" is a term that carries a great deal of polysemy. In linguistics, for example, some journals follow a double-blind peer review process (in which the author does not know the identity of the reviewers and the reviewers do not know the identity of the author). Other linguistics journals follow the model in the sciences, using single-blind review (in which the author does not know the identity of the reviewers but the reviewers do know the identity of the author).

In addition, the processes of peer review for books and for edited collections vary across disciplines. A book in the sciences is subject, typically, to editorial review without double-blind peer review. A monograph or edited collection in the humanities, on the other hand, is typically subject to editorial review as well as double- or single-blind peer review.

In other words, depending on the heterogeneity of the disciplines in your department, the term "peer review" may appear an obvious point of shared value, even though it may signify different things to each member of the department.

Regardless of that digression, the processes of identification are diminished in this second example. Placement in a tier is a result of an action, not an identity. For that reason, I refer to this model for a merit system as an atomistic model, as opposed to a holistic model. Holistic models ask members of the department to identify with a profile. Atomistic models ask members to identify actions or miracles.

Example 2 is atomistic with only one activity counted or assessed: submitting work for peer review. Example 3, also derived from a Midwestern university, takes atomistic accounting for merit to a higher level of detail (app. 3).

The first paragraphs of this merit-process document, notably, are not a preamble; they are a set of instructions. And in this exhaustive laundry list of activities, it's hard to pin down the shared priorities or values of the department as community.

Certainly, there is a value to the monograph, which results in twenty-one total points over six years. Forty book reviews in six years would not yield as many points as a book. That may feel intuitively right, but it's implicit, not explicitly stated. More complicated is judging the relative value of books and articles: a book earns about 
Designing a

Merit Process as

Intellectual Work

David Beard the same number of points as publishing a peer-reviewed article a year, every year, for seven years. One can argue either side of the equity in that, although I think that this process reflects a book culture in the department.

At a certain level, this document appears to value all possible contributions to the department. But that is surface level. This document is actually the product of a process developed over years, as new categories are added, rhizomatically: new categories have sprouted and spread, and so the department appears open to all that its members do, in the name of inclusiveness.

But whether these categories are consistent with a set of values seems less clear to me. The process of identification in the holistic model is almost entirely lost in this expanded atomistic model. I cannot tell with whom I might congregate and from whom I might segregate, as I position myself within this community. I know only that my activities are worth points.

There is a security in this system - when I complete the form, I know exactly how many points I have earned. Entire articles have been published by economists attempting to quantify faculty merit (e.g., Weistroffer et al.; Wenger and Girard).

At the same time, research warns against an overreliance on quantifiable, atomistic methods. As a committee at the University of Alberta noted: "A university evaluation system, to be effective, must avoid both the scylla of encouraging popular instruction (without emphasis on required reflective inquiry) ... as well as the Charybdis of rewarding only the quantified measure of publication of research to the detriment of both scholarship and teaching" (University of Alberta). Items we can count, like high teaching evaluation scores or number of articles, are easy, and so seductive because they are easy. But they are easy because they don't reflect the depth of our work.

I have assembled a laundry list of activities - but who am I, and what is the nature of the collective in which I am doing this work? This list does not call upon me to answer these questions. It trades common values for countability.

\section{Pacing the Work of Research: Some Comparative Notes}

These three models do offer us some interesting insight into the comparative pacing of scholarly productivity and the way we communicate expectations about a balanced, productive life.

In example 3, which privileges book culture, the best measures for productivity are that a book can be expected no more frequently than once every six years-a measure which maps against the tenure expectations (one book in the six pretenure years). Articles can be expected once per year within this system, both because they are awarded points for one year, instead of the six that a book earns, and because, as noted earlier, seven years of annual articles equals the number of points awarded for one book over six years.

In example 2, the highest level of productivity encouraged in the department is two peer-reviewed articles every three years. This is clearly a culture that privileges the article, as a book can be worth no more than two articles. But this scheme also tells us more about departmental values. 
Designing a

Merit Process as

Intellectual Work

David Beard
Beyond whether the department privileges a genre, this process also encourages scholars to remember that they have responsibilities in the classroom and to service as well. Publishing an article every year is a misdirection of energy within the value system of this department; it is not legitimated by the discourse of merit.

Example 2 also reminds us that a sense of pacing, of the arc of a career, not of a year, corrects for some of the fluctuations in annual merit allotments. As Terpstra and Honoree put it:

A faculty member with a high performance rating based upon several publications or "hits" in a lean budget year may not receive any merit money that year. In the next appraisal period, the budget may be healthier (allowing for larger merit pay distributions), but that same faculty member may have a lower appraisal based on fewer publications or "hits." For most faculty members, the number of publications typically fluctuates from one year to the next. Merit systems that make adjustments for past appraisal periods may minimize the potential problem of the "lottery effect" that can operate in universities with fluctuating annual budgets. (45)

In our second example, the scale accounts for a "lean" year in budgeting by carrying over a success into the next two years' evaluation.

In example 1, the system that makes no use of quantification at all, there is a small discussion of "chronic" underproduction, but there are no measures for annual productivity. The holistic assessment isn't asking what you did this year; it's asking who you are and whether you identify and work within the values of the department.

I find that model attractive, at the same time that I recognize that it presupposes a high level of agreement on what the job is and how the job should be done. Perhaps that requires a homogenous departmental community. Or perhaps it requires a level of trust that is hard to find in the university.

\section{What about Collaboration?}

Collaboration is primarily a problem for the atomistic approaches to merit processes. In the points-based system, there is a temptation to allot partial points, and the instructions in example 3 even demand an accounting for proportion of effort. Even in example 2, there may be a temptation, unless it's spelled out in policy, to award partial credit-requiring two collaboratively authored essays to land in category 2 , four to land in category 1.

Again, the holistic model seems most flexible; it doesn't ask one to account for collaboration as a fractional accomplishment, nor does it ask for proportion of effort. It simply asks, Are you living within the values of the department?

I'm swooning for the holistic model, but I should probably acknowledge some of its limitations before concluding.

\section{Arguing about Values Is Hard}

I feel personally drawn to the holistic model for merit allotment. I think it is simple, in that it presumes that the bulk of my colleagues are doing their job adequately. 
Designing a

Merit Process as

Intellectual Work

David Beard
Occasionally, some will succeed spectacularly; occasionally, some will fail chronically. But most, including myself, are simply doing good work. I can imagine that, in the holistic system, my department would look like a bell curve.

But that ease depends on a high level of consensus of what constitutes the work, up front, and that can be hard. As James C. Hearn notes, faculty members "may dissent on what the institution is 'all about,' and these disagreements are resolved through the acceptance of diverse, often vaguely phrased goals" (398). I've been in a lot of meetings where I can't even get agreement on whether I teach at a school with an emphasis on teaching or on research. (The forty-forty-twenty split on research, teaching, and service is really just, I think, an agreement on the devaluation of service, not an agreement on the valuation of teaching and research.)

I look at the list of values in the preamble to the holistic model and imagine that it might take a three-hour discussion simply to decide whether we, as a department, agree about the value of interdisciplinarity.

Just because a task isn't easy, though, doesn't mean we shouldn't engage in it. None of us started a dissertation believing it would be easy.

So, I want us to have difficult conversations, whether we want to use an atomistic or a holistic approach to merit. Difficult conversations will result in trust, and research into successful faculty merit systems affirms that trust is important. According to Siegall and Worth, "pay systems that tie employee pay to employee performance often fail, not because the system was designed 'wrong,' but because of a lack of trust between superiors and subordinates" (646). In departmentally determined faculty merit pay systems, that trust needs to extend to one's colleagues, who often sit on merit committees or rotate into positions as department chairs.

I think back to the faculty member who sits, disaffected, in an office-or more likely at home, avoiding the office altogether. Years of poor merit allotments have resulted in feeling undervalued. Siegall and Worth explain this phenomenon and how we can mitigate it:

There is a psychological contract between employees and their employer. . . Violations of this contract can reduce trust, . . . and as Lawler pointed out, low (or lowered) trust can negatively affect a merit system's chances at effectiveness. On the other hand, the existence of trust can mediate the impact of a broken psychological contract on an employee's future contributions. If an employee is the recipient of an unfavorable outcome (e.g. not getting the hoped-for raise), having a trusting superior-subordinate helps to mitigate the employee's response. (647)

Where does that trust come from, in the faculty merit pay process? In example 3, it comes from confidence in numbers. In example 1 , it comes from confidence in our agreements with our colleagues about the nature of our work.

If faculty members are not invested in the cocreation of the merit system as intellectual work, no matter which version they choose, atomistic or holistic, the psychological contract will break, this year or next or the year after, and the department will be poorer for it. 
Designing a

Merit Process as

Intellectual Work

David Beard

\section{Notes}

1. I can already hear some of my humanist colleagues cringing at the jargon in these passages, but I'll press on.

2. I've totally made these terms up.

\section{Works Cited}

Burke, Kenneth. A Rhetoric of Motives. U of California P, 1969.

Gill, Carol. "A Review of the Critical Perspective on Human Resource Management." Melbourne Business School Working Paper, 2007, works.bepress.com/carol_gill/11/.

Gomez-Mejia, Luis R., and David B. Balkin. "Determinants of Faculty Pay: An Agency Theory Perspective." Academy of Management Journal, vol. 35, no. 5, 1992, pp. 921-55.

Harmon, Derek J., et al. "A Model of Rhetorical Legitimation: The Structure of Communication and Cognition Underlying Institutional Maintenance and Change." Academy of Management Review, vol. 40, no. 1, Jan. 2015, pp. 76-95, doi:10.5465/amr.2013.0310.

Hearn, James C. "Pay and Performance in the University: An Examination of Faculty Salaries." The Review of Higher Education, vol. 22, no. 4, 1999, pp. 391-410.

Miller, Richard I. "Merit Pay in United States Postsecondary Institutions." Higher Education, vol. 17, no. 2, 1988, pp. 219-32.

Orgad, Liav. "The Preamble in Constitutional Interpretation." International Journal of Constitutional Law, vol. 8, no. 4, 2010, pp. 714-38, doi.org/10.1093/icon/mor010.

Siegall, Marc, and Chuck Worth. "The Impacts of Trust and Control on Faculty Reactions to Merit Pay." Personnel Review, vol. 30, no. 6, 2001, pp. 646-56, doi.org/10.1108/EUM0000000005980.

Terpstra, David E., and Andre L. Honoree. "Faculty Perceptions of Problems with Merit Pay Plans in Institutions of Higher Education." Journal of Business and Management, vol. 14, no. 1, 2008, pp. 43-59.

University of Alberta Agreement Review Committee. "An Alternative System of Career Progress and Evaluation of Performance for Faculty: Principles for Consideration.” 1991.

Weistroffer, H. Roland, et al. "A Merit Pay Allocation Model for College Faculty Based on Performance Quality and Quantity.” Economics of Education Review, vol. 20, no. 1, Feb. 2001, pp. 41-49, doi:10.1016/S0272-7757(99)00037-0.

Wenger, Robert B., and Dennis M. Girard. “A Faculty Merit Pay Allocation Model.” Research in Higher Education, vol. 41, no. 2, Apr. 2000, pp. 195-207, doi.org/10.1023/A:1007043221237.

\section{Appendix}

\section{Example 1: Holistic Matrix for Research; Doctoral-Granting Department}

\section{Preamble}

Criteria: We expect all the members of the department to publicly present their scholarship or creative works in appropriate professional venues.

Venue (significance of the press, the journal, the collection, or the occasion of the work; invited or refereed)

Scope (range and difficulty of the work; interdisciplinarity and cross-disciplinarity; historical, theoretical, ethnographic, archival, or textual breadth and intellectual depth)

Originality (command of subject, cogency of method, originality in interpretation or theory, and application of pertinent theories)

Visibility (awards and honors, grants, editorships, reviews, citations, prizes, presentations, organization of scholarly conferences, reprints, multiple editions, and translations)

\section{Profile Category 1}

This category is reserved for publications, presentations, and exhibitions of highest quality that have earned national or international visibility—e.g., major museums, lead essays in journals, 
Designing a

Merit Process as

Intellectual Work

David Beard books from major presses, international symposia, and conferences. Major grants or fellowships are evidence of this category.

\section{Profile Category 2}

This ranking includes articles appearing in scholarly journals; essays or chapters in anthologies, in festschriften, or in other collections; published lectures; and briefer essays, including reviews. Also included here is whether a faculty member has organized, chaired, or participated in conferences; delivered papers; and received internal grants. Faculty members in this category have a record of steady, informative publishing in appropriate academic venues.

\section{Profile Category 3}

This category applies to faculty members who are chronically unproductive and who have little or nothing on the public record.

\section{Example 2: Simplified Atomistic Matrix for Research; Undergraduate Department}

\section{Commentary}

Category 1. Scholar has published two or more peer-reviewed pieces of scholarship in the last three years.

Category 2. Scholar has published one peer-reviewed piece of scholarship in the last three years.

Category 3. Scholar has submitted research to a peer-reviewed journal or conference in the last year.

\section{Example 3: Expanded Atomistic Matrix for Research}

Publications, presentations, literary activities, etc. List only publications that actually appeared during this year. Include in your portfolio a copy of each publication counted below; give full bibliographical information if that does not appear on the publication. To save the committee time, consult the MLA Directory of Periodicals and attach printed or documented prestige claims from there and anywhere else, as appropriate.

Provide in the appropriate space or on the back of these sheets details about papers delivered, colloquia or literary readings organized, etc. (date, place, sponsoring institution). If your research is coauthored, explain clearly the extent of your own contribution to the project in order to demonstrate a major contribution.

\section{Print Research and Creative Activities}

Long scholarly book, novel, major collection of poems or stories published. 6/5/4/3/2/1 over six years. List work and year published:

Edited scholarly book published. 3/2/1 over three years. List book and year published:

Textbook or general audience book published. 2/1 points over two years. List book and year published:

Scholarly monograph or literary chapbook (50-120 pages) published. 4/3/2/1 over four years. List work and year published: 
Designing a

Merit Process as

Intellectual Work

David Beard
Short scholarly book or literary work (approximately 150 pages) published. 5/4/3/2/1 over five years. List work and year published:

Contributing editor for a collection of essays. 2-3 points; make the case for one or the other

Paper published by refereed scholarly journal.

Typically 3 points; $2-4$ depending on journal, size, and scope of paper, etc.

Discussion note published in refereed scholarly journal.

2 points

Review essay (5+ pages) published in refereed scholarly journal. 2 points

Book review published in refereed scholarly journal. 0.5 points each

Literary work published by magazine or journal.

2-4 points depending on magazine or journal and nature of the work

Paper published in general audience journal or magazine or public program produced in other media or forms.

2 points

Review, op-ed piece, discussion piece in newspaper, general audience magazine, nonrefereed journal (limit: 4 points total).

0.25 points each

Reference book or dictionary entry. If one has done dozens of long ones of high quality during the time covered for merit, then supply the copy to the committee, list 4 points here, and request additional points in the space at the end of the research section.

0.75 points each (limit: 4 points)

Original essay or literary work published in an anthology.

2 points

Previously published essay or literary work reprinted in an anthology.

1 point

Review for CHOICE or equivalent review squibs.

0.5 points each

\section{Research Grants}

Sabbatical (3 points)

Single-semester leave (1.5 points)

Summer fellowship of about $\$ 10,000$ (1 point)

Internal grant of $\$ 10,000$ or more (1 point)

College research award ( 2 points)

Other small research grants, up to $\$ 3,000$ ( 0.5 points each for a maximum of 1.5 points) 
Designing a

Merit Process as

Intellectual Work

David Beard

\section{Oral Research and Creative Activities}

Paper(s) delivered, literary reading(s) or talk(s) (invited) at international or national or major scholarly or professional meeting(s).

2 points

Paper or talk given at regional conference or another university.

$$
1 \text { point }
$$

Paper or talk given to another department.

0.25 points

Management or organization of colloquia series or organization of conferences and conference sessions:

Organize program for international conference (3-4 points)

Organize international or national conference session (2 points)

Chair international or national session (1 point)

Organize program for local or regional session (1 point)

Chair local or regional session ( 0.5 points)

Literary readings of one's own work (other than those at national conferences).

points to be determined by Merit Committee (below or on back of this page, describe the occasion-e.g., invited reading or open-mic performance—work[s] read, location, sponsor, attendance, etc.; 0.25 points for local reading, 0.5 points for state reading; limit of 1.5 total points, though you can present a case for additional points)

\section{Recognition}

Recognition by one's peers for scholarship or literary excellence. Includes prizes, reviews in scholarly journals, citations of your work in the field, feature articles, etc. Submit documentation (e.g., reviews) in your portfolio.

points to be determined by Merit Committee

\section{Other research-related items (detail on back of this page or insert sheets)}

points to be determined by Merit Committee (though you may recommend number here) 